\title{
Nível de Percepção do Projeto Politico-Pedagógico: O que Pensam os Profissionais de Educação Contábil de Uma Instituição de Ensino Superior Pública do Estado da Bahia/Brasil
}

\author{
Level of Perception of the Political-Pedagogical Project: the Professionals \\ Think of Accounting Education in a Higher Education Institution Public \\ Bahia/Brazil \\ Isac Pimentel Guimarães \\ Mestrando em Educação (UFBA) \\ Sônia Maria da Silva Gomes \\ Doutora em Engenharia da Produção (UFSC) \\ Professora Titular da UFBA \\ Professora do Programa de Mestrado da \\ Vilma Geni Slomski \\ Ph.D em Controladoria e Contabilidade (USP) \\ Doutora em Educação (USP) \\ Professora do Programa de Mestrado da FECAP \\ Antônio Carlos Ribeiro da Silva \\ Dr. em Educação (Universidade de Minho - \\ Portugal) \\ Professor da FVC/UFBA/UEFS
} UFBA

\begin{abstract}
Resumo
O presente trabalho busca investigar o nível de percepção dos professores de Ciências Contábeis da Universidade Federal da Bahia (UFBA), acerca do Projeto Político-Pedagógico. Com o propósito de atingir o objetivo circunscrito nesta investigação, optou-se em desenvolver uma pesquisa empírica, utilizando o questionário em escala Likert de 1 a 7 como técnica de coleta de dados, no qual 22 dos 28 profissionais de ensino, do curso de Ciências Contábeis, responderam ao questionário proposto. Tendo em vista que as discussões foram realizadas com respaldo na literatura existente, a pesquisa identificou o nível de percepção dos professores com base nos seguintes critérios: i) concentração de pontos da escala Likert acima de 4 = Nível de percepção satisfatório; ii) concentração de pontos da escala Likert sobre o ponto 4 = Nivel de percepção em neutralidade; iii) concentração de pontos da escala Likert abaixo de $4=$ Nivel de percepção insuficiente. Com efeito, constatou-se que os docentes expressam um nível de percepção bastante satisfatório no que diz respeito a conceitos, interdiscplinaridade, currículo, planos de ensino, implantação e consolidação do PPP, uma vez que corroboram, em sua maioria, com a idéia de que esse documento deve abranger reflexões em torno das seguintes dimensões: estrutural e conjuntural da sociedade; ética-valorativa; historicidade da instituição e; processo de conhecimento. Além disso, verificou-se que em meio ao quadro de professores permanentes e substitutos, prevalece a figura masculina em quantidade, formação contábil, maior nível acadêmico e atuação em coordenação de curso.
\end{abstract}

Palavras-chave: Projeto Político-Pedagógico, Educação Contábil, Percepção.

\section{Abstract}

This study aims to investigate the level of teachers' perception of Accounting Sciences, Federal University of Bahia (UFBA), about the political-pedagogical project. In order to achieve the limited objective of this investigation, we decided to develop an empirical research, using the questionnaire in Likert scale between 1 to 7 as technical data collection, in which 22 of the 28 professional education, travel Sciences Accounting, responded to questions posed. Given that discussions were held with support in the literature, this study 
identified the level of teachers' perception on the following criteria: i) concentration of points above the Likert scale of $4=$ satisfactory level of awareness, ii) concentration point Likert scale on point $4=$ Level of awareness on neutrality iii) concentration of points below the Likert scale of $4=$ inadequate level of perception. Indeed, it was found that teachers expressed a level of awareness quite satisfactory with regard to concepts, interdisciplinarity, curriculum, teaching plans, implementation and consolidation of the PPP, as corroborated, mostly with the idea of that document should include discussions on the following dimensions: structural and economic society, ethics, evaluative, and historicity of the institution; process knowledge. Moreover, it was found that amid the framework of permanent teachers and substitutes, the male prevails in quantity, accounting training, higher academic level and experience in coordination of course.

Keywords: Political-Pedagogical Project, Accounting Education, Perception.

\section{INTRODUÇÃO}

O Projeto Político-Pedagógico (PPP) foi um dos principais resultados das modificações ocorridas, nas orientações das políticas educacionais brasileiras, a partir dos anos 80 do século XX. Estas mudanças encontram-se expressas na nova Lei de Diretrizes e Bases da Educação Nacional - Lei no 9.394/96 - e em linhas gerais, convergem para a adoção de novos modelos de gestão e planejamento da educação, calcados em formas mais flexíveis e descentralizadas de administração.

Ao se questionar o desempenho do profissional formado pela universidade é a qualidade do ensino ministrado que concretamente está em avaliação. Neste sentido é que caminha a reforma universitária, onde a LDB (1996) traz orientações governamentais para direcionar o processo de formação humana, via a direção e centralização da orientação curricular sob os auspícios do Estado - nos Projetos de Escolarização do Sistema Nacional de Educação Superior (DCN).

A LDB (1996) em seu capítulo IV, Art. 43․ I., indica que a finalidade da educação é "estimular a criação cultural e o desenvolvimento do espírito científico e do pensamento reflexivo". No Título I - Da Educação, $\S 2^{\circ}$ consta que "a educação escolar deverá vincular-se ao mundo do trabalho e à prática social". Isto indica as dimensões da vida ou contextos valorizados pela LDB: o trabalho e a cidadania ativa para o exercício consciente dos direitos e deveres, em especial a educação no processo de construção social ${ }^{\mathbf{1}}$.

Nesta direção estrutura-se o plano deste artigo, e, assim, levanta-se o seguinte questionamento: $O$ que pensam os professores de Ciências Contábeis da UFBA, acerca dos pressupostos filosófico-sociológico, epistemológico e didático-metodológico do Projeto Político-Pedagógico? Em vista disso, vê-se que educar na diversidade constitui um desafio de superar a postura individual em favor de um projeto coletivo, no qual a formação continuada emerge como eixo norteador de múltiplas atividades. Assim, o presente trabalho tem o objetivo investigar o nível de percepção dos professores de Ciências Contábeis da Universidade Federal da Bahia (UFBA), acerca do Projeto Político-Pedagógico.

Discutir sobre Projeto Pedagógico não é novidade, uma vez que o PPP da IES ou do curso sempre existiu. Entretanto, a falta de participação coletiva dos professores na sua elaboração e a falta de clareza na compreensão da idéia de "projeto", favorece sua implantação de forma burocrática e fragmentada. Esta era a essência da LDB/68, Lei 5692, a

\footnotetext{
${ }^{1}$ O Ministério da Educação e Cultura (MEC) promulgou a Resolução No 10, CNE/CES, de 16 de dezembro de 2004. Em seu artigo $2^{\circ}$ revela a preocupação em atribuir autonomia e flexibilidade ao ensino, e apresenta a proposta de alteração dos currículos dos cursos de graduação em Ciências Contábeis no Brasil.
} 
qual solicitava apenas o cumprimento das orientações emanadas do poder central. É deste ponto de vista que se pretende tratar a questão do PPP nos cursos de Ciências Contábeis. A formação de contadores globalizados remete à discussão sobre a construção de um projeto pedagógico do curso e a elaboração de currículos próprios adequados ao atual cenário econômico, em que a formação dos profissionais possa responder aos desafios que o mundo lhes coloca.

\section{FUNDAMENTAÇÃO TEÓRICA}

\subsection{Reflexões acerca do Projeto Político-Pedagógico}

A configuração PPP constitui-se um processo democrático de decisões que preocupa instaurar uma forma de organização do trabalho pedagógico que supere os conflitos, buscando eliminar as relações competitivas, corporativas e autoritárias e, por sua vez, rompendo com a rotina do mando impessoal e racionalizado da burocracia que permeia as relações no interior da IES e os efeitos fragmentários da divisão do trabalho que reforça as diferenças e hierarquiza os poderes de decisão.

Nesta perspectiva, o PPP vai além de um simples agrupamento de planos de ensino e de atividades diversas. O projeto não é algo que é construído e em seguida arquivado ou encaminhado as autoridades educacionais como prova do cumprimento de tarefas técnicoburocráticas. Ele é construído e vivenciado em todos os momentos, por todos os envolvidos com o processo educativo da universidade e, com efeito, visto como instrumento vivo de referências para nortear ações efetivas na indissociabilidade do ensino-pesquisa-extensão, para melhoria do curso de Ciências Contábeis (LAFFIN, 2004; VEIGA, 2005).

A principal possibilidade de construção do PPP passa pela relativa autonomia das IES e de sua capacidade de delinear sua própria identidade. Isso significa resgatar a instituição como espaço democrático, lugar de diálogo, fundado na reflexão coletiva. Assim sendo, para Vasconcelos (2006), o PPP deve ser entendido como a sistematização, nunca definitiva, de um processo de Planejamento Participativo, que se aperfeiçoa e se concretiza na caminhada, que define claramente o tipo de ação educativa que se quer realizar. É um instrumento teórico-metodológico para a intervenção e mudança da realidade.

Para Veiga (2004) o PPP, enquanto organização do trabalho, deverá está fundamentado nos princípios que deverão nortear a instituição democrática, pública e gratuita. Os princípios norteadores estão sintetizados no Quadro 1.

\begin{tabular}{|c|l|}
\hline $\begin{array}{c}\text { Princípios } \\
\text { Norteadores }\end{array}$ & \multicolumn{1}{c|}{ Definições } \\
\hline Igualdade & $\begin{array}{l}\text { A Igualdade de oportunidades requer mais que a expansão quantitativa de ofertas, requer } \\
\text { ampliação do atendimento com simultânea manutenção de qualidade. }\end{array}$ \\
\hline Qualidade & $\begin{array}{l}\text { O desafio que se coloca ao PPP da escola é o de propiciar uma qualidade para todos, uma } \\
\text { qualidade que implica em duas dimensões indissociáveis: a formal ou técnica e a política; }\end{array}$ \\
\hline $\begin{array}{c}\text { Gestão } \\
\text { democrática }\end{array}$ & $\begin{array}{l}\text { É o princípio consagrado pela constituição vigente e abrangem as dimensões pedagógicas, } \\
\text { administrativas e financeiras; exige a compreensão em profundidade dos problemas postos } \\
\text { pela prática pedagógica, visando romper com a separação entre concepção a execução, } \\
\text { entre o pensar e o fazer, entre teoria e prática. }\end{array}$ \\
\hline Liberdade & $\begin{array}{l}\text { A autonomia e a liberdade fazem parte da própria natureza do ato pedagógico. O } \\
\text { significado de autonomia remete para regras e orientações criadas pelos próprios sujeitos } \\
\text { da ação educativa, sem imposições externas. }\end{array}$ \\
\hline $\begin{array}{c}\text { Valorização do } \\
\text { magistério }\end{array}$ & $\begin{array}{l}\text { E o princípio central na discussão do PPP; A qualidade do ensino ministrado na escola e } \\
\text { seu sucesso na tarefa de formar cidadãos capazes de participar da vida socioeconômica, } \\
\text { política e cultural do país. }\end{array}$ \\
\hline
\end{tabular}

Quadro 1: Princípios Norteadores do PPP.

Fonte: Elaborado pelo autor, 2009.

R. Cont. Ufba, Salvador-Ba, v. 4, n. 3, p. 4-19, setembro-dezembro 2010 
Não obstante, o PPP exige profunda reflexão sobre as finalidades da educação, assim como a explicitação de seu papel social e a clara definição de caminhos, formas operacionais e as ações a serem empreendidas por todos os envolvidos com o processo educativo. Seu processo agultinará crenças, convicções, conhecimento da comunidade, do contexto social e científico, constituindo-se em compromisso político e pedagógico coletivo. Para Arroyo (1994), a escola constrói sujeitos coletivos de vivências humanizadoras, de valores, de interações, de linguagens múltiplas, de comunicação, de pesquisa-produção, de interação com a cidadania e com a multiplicidade de processos de produção-reprodução (McCLELLAND, 1973; KWIEK, 2001 e WALLACE, 2003).

Neste sentido, as IES deverão estabelecer a organização curricular por meio de Projeto Pedagógico, com descrição dos seguintes aspectos: a) I - perfil profissional esperado para o formando, em termos de competências e habilidades; b) II - componentes curriculares integrantes; c) III - sistema de avaliação do estudante e do curso; d) IV - estágio curricular supervisionado; e) V - atividades complementares; f) VI - monografia, projeto de iniciação científica ou projeto de atividade - como Trabalho de Conclusão de Curso (TCC) componente opcional da instituição; g) VII - regime acadêmico de oferta; h) VIII - outros aspectos que tornem consistente o referido projeto.

A descrição dos aspectos do Projeto Pedagógico que as IES devem seguir torna clara a tentativa de formar profissionais qualificados. Mas sabe-se dos problemas que ainda persistem e que impedem que a alteração curricular cumpra a proposta de "atribuir uma autonomia e flexibilidade", sugerida pelas DCN.

Assim, a construção do PPP, comprometido com a melhoria da qualidade de ensino, passa pela melhoria da universidade sobre a condição dos indivíduos como sujeitos sociais. Especificamente em relação ao aluno, deve oportunizar a apropriação dos conhecimentos humanos e técnicos historicamente produzidos, na perspectiva de melhor contribuir para sua inserção crítica no contexto das relações sociais, em nível macro, como um ser que se humaniza, cada vez mais. Nesse enfoque, a escola não pode restringir suas práticas avaliativas à questão administrativa, uma vez que a perspectiva burocrática não é, de forma alguma, o mundo do conhecimento (DEMO, 1997).

Como pode ser analisado no Quadro 2, no decorrer do processo de construção do PPP, Veiga (2004) considera dois momentos interligados e permeados pela avaliação: o da concepção e o da execução.

\begin{tabular}{|l|l|}
\hline \multicolumn{1}{|c|}{ Concepção } & \multicolumn{1}{c|}{ Execução } \\
\hline Processo participativo e de decisões & Nasce da própria realidade \\
\hline Desvela os conflitos e as contradições & É exeqüível e contempla a avaliação \\
\hline Princípios baseados na autonomia e solidariedade & Ação articulada de todos os envolvidos \\
\hline Compromisso com a formação do cidadão & É construído continuamente \\
\hline
\end{tabular}

Quadro 2: Concepção e Execução do PPP.

Fonte: Elaborado pelo autor, 2009.

Assim, o PPP aponta o rumo, a direção, o sentido explícito para um compromisso estabelecido coletivamente. $\mathrm{O}$ projeto pedagógico, ao se constituir em processo participativo de decisões, preocupa-se em instaurar uma forma de organização do trabalho pedagógico que desvele os conflitos e as contradições, buscando eliminar as relações competitivas, corporativas e autoritárias, rompendo com a rotina do mando pessoal e, por sua vez, permitindo as relações horizontais no interior da universidade.

Dessa forma, o PPP é composto de três partes articuladas entre si: marco referencial, Diagnóstico e Programação, conforme detalhado no Quadro 3. 


\begin{tabular}{|c|c|c|}
\hline Marco Referencial & Diagnóstico & Programação \\
\hline $\begin{array}{l}\text { O que queremos alcançar? } \\
\text { Essa pergunta deve encontrar } \\
\text { respostas na visão que na Instituição } \\
\text { que o planeja tem de Mundo, de } \\
\text { Homem, de Escola, de sociedade e das } \\
\text { características das ações educativas } \\
\text { que devem ser implementadas }\end{array}$ & $\begin{array}{l}\text { O que nos falta para ser o que } \\
\text { desejamos? } \\
\text { Após mapaear as necessidades } \\
\text { da IES deve-se elaborar as } \\
\text { metas que pretende para atingir } \\
\text { os objetivos previamente } \\
\text { delineados. }\end{array}$ & $\begin{array}{l}\text { O que faremos concretamente } \\
\text { para suprir tal falta? } \\
\text { É a ação efetiva para que os } \\
\text { objetivos possam ser } \\
\text { alcançados. É a procura dos } \\
\text { meios necessários para atingir } \\
\text { as metas. }\end{array}$ \\
\hline
\end{tabular}

Quadro 3: Componentes do PPP

Fonte: Adaptado Vasconcelos (2006, p.170)

O envolvimento e o comprometimento com o PPP devem revelar não apenas uma concepção própria do que seja o processo ensino-aprendizagem, mas fundamentalmente uma compreensão e uma apropriação do trabalho em educação. A apropriação do trabalho em educação implica objetivar o PPP no sentido de garantir um processo de reflexão da ação, da organização do trabalho e das relações do curso de Ciências Contábeis com a instituição universitária (DEWEY, 1916 e FREIRE, 2007).

Assim, o PPP é uma ação intencional, com um sentido explícito, com um compromisso defendido coletivamente. Por isso, todo PPP é também, um projeto político por estar intimamente articulado ao compromisso sóciopolítico com os interesses reais e coletivos da população majoritária. É político no sentido de compromisso com a formação do cidadão para um tipo de sociedade (VEIGA, 2004). Na dimensão pedagógica reside a possibilidade da efetivação da intencionalidade da universidade, que é a formação do cidadão participativo, responsável, compromissado, crítico e criativo. Pedagógico, no sentido de definir as ações educativas e as características necessárias às escolas de cumprirem seus propósito e sua intencionalidade, Figura 1.

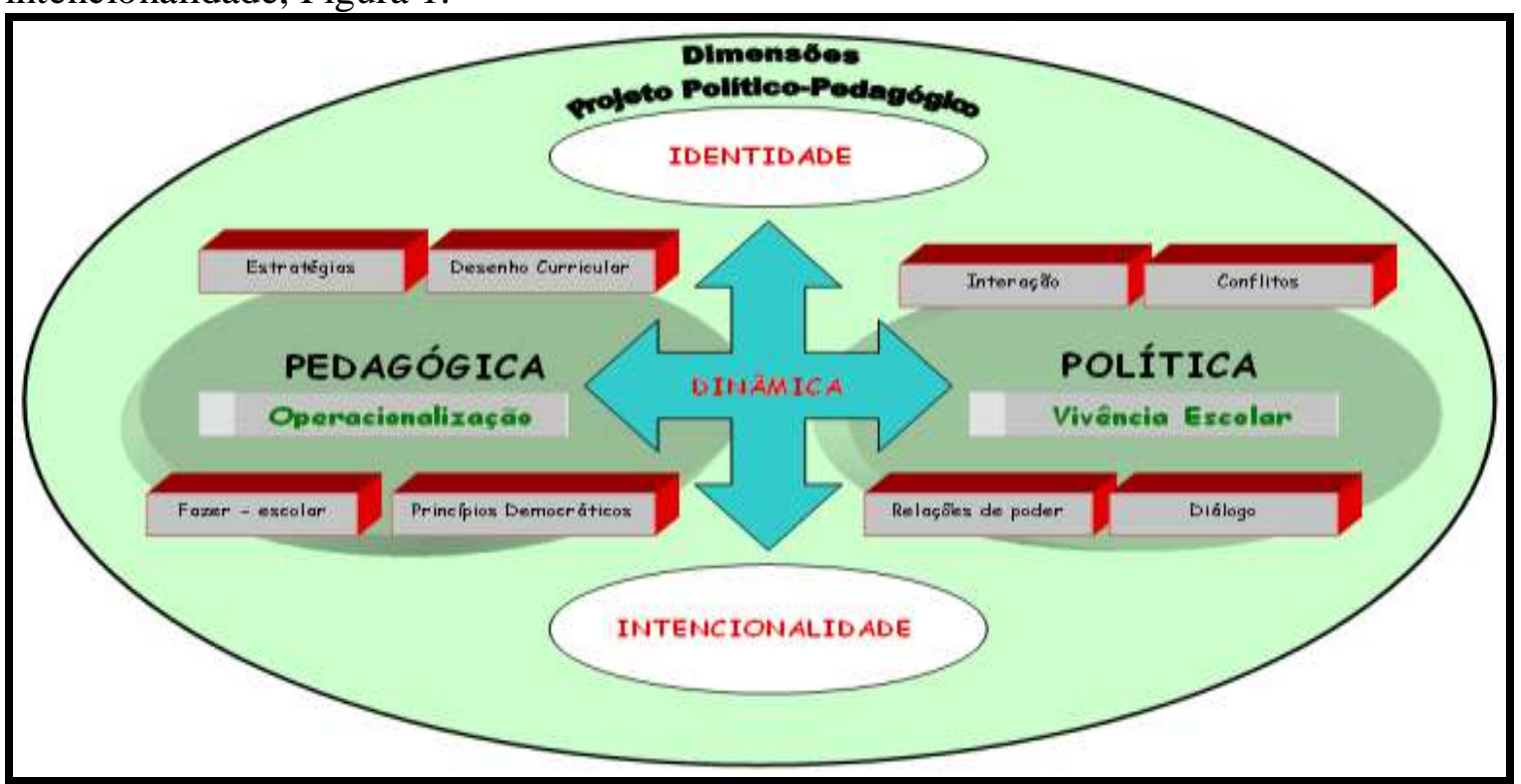

Figura 1: Dimensões do PPP

Fonte: Elaborado pelo autor, 2009.

Assim, o PPP é uma ação intencional, com um sentido explícito, com um compromisso defendido coletivamente. Na dimensão pedagógica reside a possibilidade da efetivação da intencionalidade da universidade, que é a formação do cidadão participativo, responsável, compromissado, crítico e criativo. Pedagógico, no sentido de definir as ações 
educativas e as características necessárias às escolas de cumprirem seus propósito e sua intencionalidade ${ }^{2}$.

\section{PROCEDIMENTOS METODOLÓGICOS}

A pesquisa desenvolvida teve caráter descritivo, uma vez que seu objetivo principal foi a descrição das características de determinada população ou fenômeno, mantendo relações entre as variáveis. Esse tipo de pesquisa exige do pesquisador certo grau de responsabilidade para que possua validade científica. Para isso, se faz necessária delimitação de técnicas, métodos, modelos e teorias que orientarão a coleta e a interpretação dos dados (SILVA, 2006).

A fim de contemplar o objeto e os objetivos propostos, o tipo de pesquisa desenvolvida neste trabalho foi sob a forma do estudo de caso, onde a forma da pesquisa qualitativa que se configura como o estudo de um caso, seja simples e específico ou complexo e abstrato, mas sempre bem delimitado e com seus contornos claramente definidos no desenvolvimento do estudo. Lüdke e André (1986) inferem ainda que no estudo de caso todos os dados da realidade são considerados importantes. A análise dos dados neste tipo de pesquisa tende a seguir um processo indutivo. Não há a preocupação "[...] em buscar evidências que comprovem hipóteses definidas antes do início dos estudos. As abstrações se formam ou se consolidam basicamente a partir da inspeção dos dados num processo de baixo para cima." (LÜDKE; ANDRÉ, 1986, p.13; YIN, 2006).

$\mathrm{O}$ instrumento utilizado para coleta de dados foi o questionário, que teve por finalidade investigar o nível de percepção dos professores de Ciências Contábeis da Universidade Federal da Bahia (UFBA), acerca do Projeto Político-Pedagógico. Para tanto, o referente questionário foi composto de três blocos: no primeiro procurou-se verificar o perfil do professor de Ciências Contábeis da UFBA; no segundo analisar os precedentes do projeto político-pedagógico e, posteriormente, constatar o nível de percepção do professor de Ciências Contábeis dentro da IES onde desempenha suas atividades enquanto professor.

A seguir é apresentado com base na Quadro 4, o formato em escala Likert das questões que comporam o questionário. A escala propunha pontos de 1 (Discordo Totalmente) a 7 (Concordo Totalmente), acerca de diversas proposições que lhes foram apresentadas, na qual o ponto 4(quatro) seria o ponto intermediário. Assim, a pesquisa analisou o nível de percepção dos professores da seguinte forma: i) concentração de maior quantidade de ponto da escala Likert acima de 4(quatro) = Nível de percepção satisfatório; ii) concentração de maior quantidade de ponto da escala Likert sobre o ponto 4(quatro) = Nível de percepção em neutralidade; iii) concentração de maior quantidade de ponto da escala Likert abaixo de 4(quatro) = Nível de percepção insuficiente.

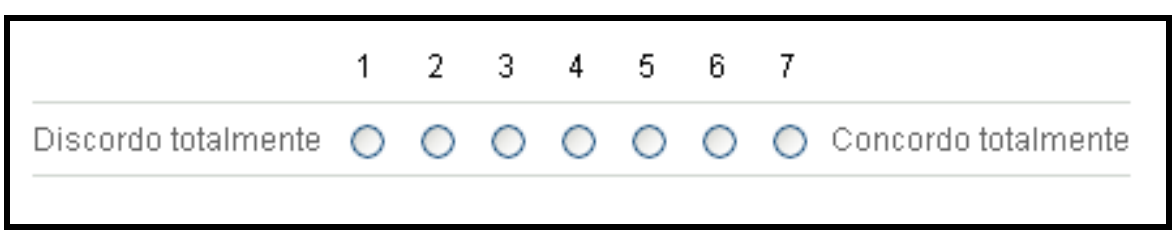

Figura 2: Escala formato Likert

\footnotetext{
${ }^{2}$ Em seu Livro “Projeto Político-Pedagógico: uma construção possível”, da Papirus, 2004, Ilma P. Veiga afirma de forma especial que o PPP é também, um projeto político por estar intimamente articulado ao compromisso sóciopolítico com os interesses reais e coletivos da população majoritária. É político no sentido de compromisso com a formação do cidadão para um tipo de sociedade.
} 
Com efeito, a escolha da Faculdade de Ciências Contábeis da UFBA para representar o presente estudo de caso sobre a percepção do PPP foi intencional, sendo basicamente determinada pelo fato da mesma representar referencial em qualidade de ensino, pois o curso possui indicações consecutivas ao Guia do Estudante - 5(cinco) estrelas (referência nacional ao estudante que pretende ingressar na universidade); conceito 4(quatro) no ENADE; maior quadro de professores permanentes com mestrado e doutorado; diversos cursos de PósGraduação em Ciências Contábeis (lato e stricto sensu) e, principalmente, o critério de acessibilidade às informações junto aos professores.

Tabela 1: Universo da pesquisa

\begin{tabular}{c|l|l|r}
\hline \multirow{2}{*}{ Professores } & \multicolumn{1}{|c|}{ Permanentes } & \multicolumn{1}{|c}{ Substitutos } & \multicolumn{1}{c}{ TOTAL } \\
\cline { 2 - 4 } & $\mathbf{2 1}$ & $\mathbf{0 7}$ & $\mathbf{2 8}$ \\
\hline \multirow{3}{*}{ Nível Acadêmico } & 06 Especialistas & 06 Especialistas & 12 \\
\cline { 2 - 4 } & 06 Mestres & 01 Mestre & 07 \\
\cline { 2 - 4 } & 09 Doutores & 0 Doutor & 09 \\
\hline
\end{tabular}

Fonte: Departamento de Ciências Contábeis - UFBA, out./2009

Desta forma, tendo por base os critérios selecionados acima enquanto fundamentais para escolha do estudo de caso realizado, é pertinente informar que os questionários foram aplicados via on-line onde os professores recebiam, através do endereço eletrônico fornecido pelo departamento de ciências contábeis, um link de acesso ao questionário. Assim, obedecendo ao Quadro 5, foi encaminhado 28(vinte e oito) questionários dos quais 24(vinte e quatro) retornaram, onde $\mathbf{0 2}$ (dois) foram descartados por algumas questões não apresentarem posicionamento na escala de Likert.

\section{ANÁLISE E INTERPRETAÇÃO DOS DADOS DA PESQUISA 4.1 Perfil do Professor}

O Bloco 1 do questionário procurou evidenciar o perfil do profissionais de ensino da Faculdade de Ciências Contábeis da UFBA. O referido bloco, expresso pelo Quadro 6, demonstra predominância significativa de professores do sexo masculino (82\%), enquanto que a parcela do sexo feminino é bastante inferior (18\%). Embora este painel encontre-se em mudança, isto retrata, em essência, a pouca atuação de mulheres na área do ensino contábil.

Tabela 2: Perfil dos professores

\begin{tabular}{c|l|c|c}
\hline \multirow{2}{*}{ Gênero } & \multicolumn{1}{|c|}{ Feminino } & Masculino & TOTAL \\
\cline { 2 - 4 } & $\mathbf{0 4}(\mathbf{1 8 \%})$ & $\mathbf{1 8}(\mathbf{8 2 \%})$ & $\mathbf{2 2}(\mathbf{1 0 0 \%})$ \\
\hline \multirow{2}{*}{ Atuação em Coordenação } & \multicolumn{10}{|c|}{03} & 06 & $53 \%$ \\
\hline \multirow{3}{*}{ Nível Acadêmico } & 01 Especialista & 08 Especialistas & $41 \%$ \\
\cline { 2 - 4 } & 02 Mestres & 04 Mestres & $27 \%$ \\
\cline { 2 - 4 } & 01 Doutora & 06 Doutores & $32 \%$ \\
\hline
\end{tabular}

Fonte: Dados da pesquisa, out./2009

Outro aspecto relevante diz respeito à atuação do professores em coordenação pedagógica, onde se que somente $53 \%$ dos professores tiveram a referida atuação. A IES é o ponto de encontro dos profissionais envolvidos na ação educativa e o professor-coordenador do curso é um intelectual orgânico no grupo, sua "práxis" (ação-reflexão-ação) abarca as dimensões reflexiva, organizativa, conectiva, interativa e avaliativa. Com relação ao nível 
acadêmico, vê-se que prevalece maior número de docentes com apenas especialização (41\%), doutores $(32 \%)$ e mestrado $(27 \%)^{3}$.

Em consonância com o que foi discutido acerca o bloco 1 da pesquisa, os dados do Quadro 7 demonstram o Tempo de Docência no Ensino Superior x Gênero, expressando que, além dos homens comporem maior parte do quadro de professores ( $82 \%$ ), como já visto, possuem também maior tempo lecionando no Ensino Superior com uma escala de tempo de docência de 17 a 40 anos. Por outro lado, as mulheres apresentam-se em pequena quantidade e com tempo relativamente inferior aos homens, 06 a 18 anos.

Tabela 3: Tempo de Docência do Ensino Superior

\begin{tabular}{c|c|c}
\hline \multirow{2}{*}{ Gênero } & Feminino & Masculino \\
\cline { 2 - 3 } $\begin{array}{c}\text { Tempo de Docência } \\
\text { (anos) }\end{array}$ & $\mathbf{0 4}(\mathbf{1 8 \%})$ & $\mathbf{1 8}(\mathbf{8 2 \%})$ \\
\hline
\end{tabular}

Fonte: Dados da pesquisa, out./2009

Todas essas discussões confirmam o papel essencial da universidade que é zelar qualidade do trabalho acadêmico que realiza e pela competência dos profissionais que forma, cabendo às coordenações de curso de graduação, a gestão didático-pedagógica do ensino, o gerenciamento da aprendizagem dos alunos e a melhoria da qualidade do profissional formado pela universidade.

\subsection{Precedentes do Projeto Político-Pedagógico (PPP)}

A busca dos precedentes que hoje denominamos como PPP leva ao passado recente do início dos anos de 1980. No referido período, o Estado brasileiro via-se as voltas de uma profunda crise fiscal, sendo "[...] incapaz de se financiar internamente senão via ganhos de senhoragem [...]." (ZAULI, 2003, p.44). A dependência econômica do Estado frente às agências internacionais de financiamento fez com que passasse "[...] a ser apontado como uma instituição morosa, pesada e ineficiente [...]" (Oliveira, 1997, p.86) frente à excelência e à eficácia do mercado.

O envolvimento de todos os intervenientes na elaboração do PPP ainda representa um grande desafio para a instituição educativa, pois esta tende, no decorrer da elaboração, a excluir a participação efetiva dos pais e dos funcionários e a trabalhar apenas com os sujeitos efetivamente envolvidos com o trabalho pedagógico, isto é, com os professores e os gestores.

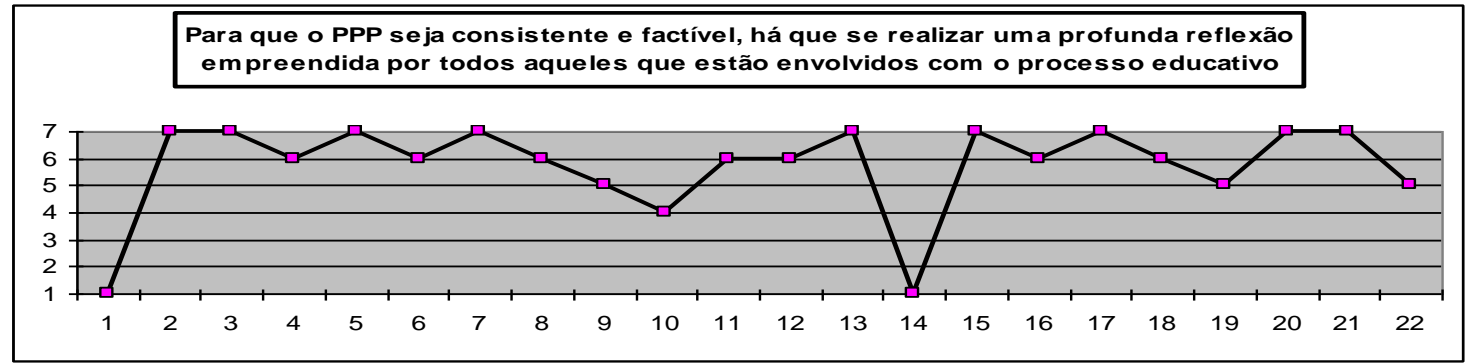

Gráfico 1: PPP: reflexão e processo educativo

Fonte: Dados da pesquisa, 2009.

\footnotetext{
${ }^{3}$ É necessário levar em consideração aqui que, embora a faculdade de Ciências Contábeis da UFBA apresente maior número de professores especialistas, o quadro se apresenta em fase de transição, ou seja, grande parte destes profissionais em exercício encontra-se em programas de mestrado, assim como os professores com titulo de mestre que se encontram em programa de doutorado.
} 
Desta forma, à luz da pergunta evidenciada no Gráfico 1, pode-se perceber que para os professores da FCC/UFBA, o PPP é um instrumento que possibilita reflexão do processo educativo consistente e factível, pois concordam que o mesmo deve realizar uma profunda reflexão empreendida por todos aqueles que estão envolvidos com o processo educativo diretor, coordenador, professor, funcionário e aluno (Nível de Percepção Satisfatório).

Nessa perspectiva, pode-se inferir que o projeto político-pedagógico se caracteriza enquanto um documento que deve traduzir as intenções de ação futuras, próximas e longínquas da instituição educativa, tendo em vista a formação do cidadão para atuar em um determinado tipo de sociedade.

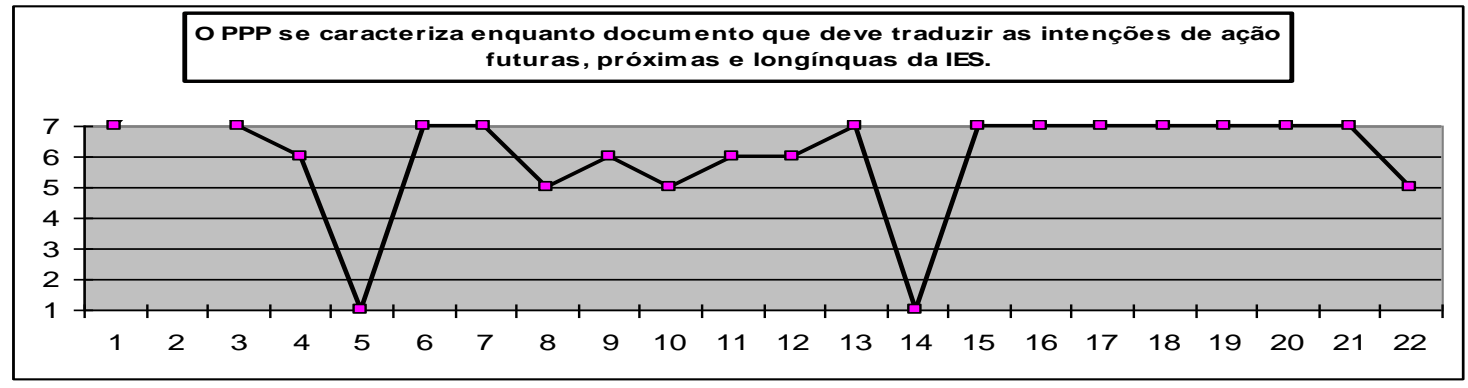

Gráfico 2: PPP: conceito

Fonte: Dados da pesquisa, 2009.

No que diz respeito ao conceito de PPP, a pesquisa revelou, Gráfico 2, que os professores em sua grande maioria concordam com o enunciado defendido pela literatura, indo ao encontro de Veiga(2005, p.12) quando afirma que para tal, faz-se necessário ponderar sobre o passado e o presente da instituição educativa a fim de projetar o possível e de "[...] antever um futuro diferente do presente $[\ldots]$ ".

Elaborado o PPP, "[...] sua existência não encerra o processo, nem acarreta resultado final. Ao contrário, sempre faz reiniciar a discussão no meio termo entre o "envolvimento e a criatividade crítica", "avaliação e aperfeiçoamento" (BUSSMANN, 1996, p.38). Segundo Gandin e Gandin (2003, p.38), o planejamento "[...] é o processo de transformar idéias em ação, ou seja, é o processo e intervir na realidade existente [...] transformando estruturas."

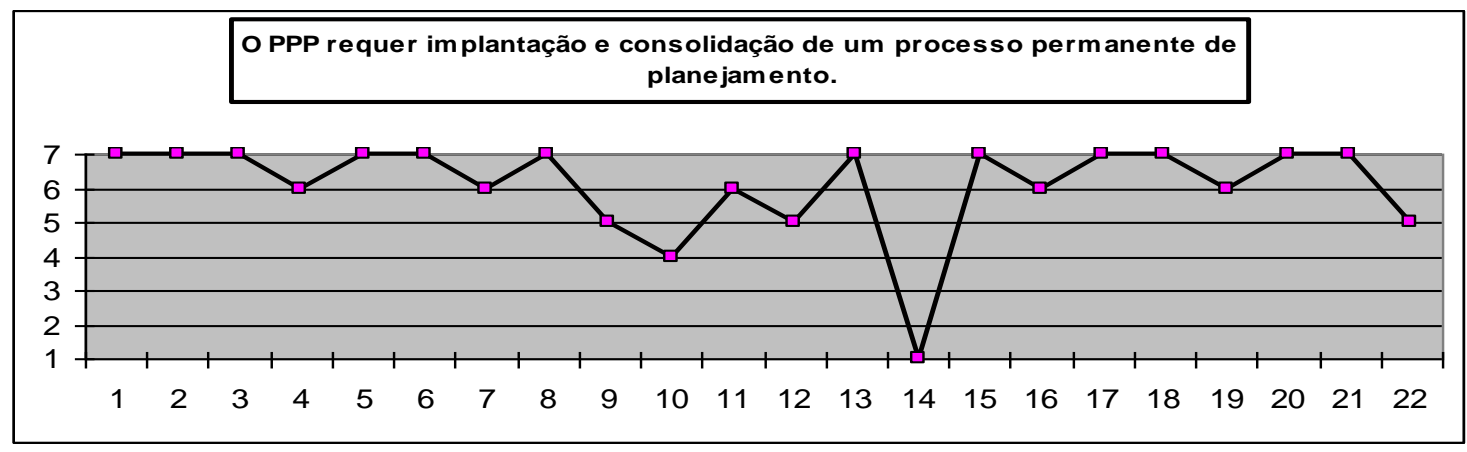

Gráfico 3: PPP: planejamento e implantação

Fonte: Dados da pesquisa, 2009.

De acordo com o Grafico 3, os respondentes mostraram um nível de percepção satisfatório com relação a implantação e consolidação do PPP, pois cultivar o projeto político enquanto fonte de inspiração requer, segundo Rossa (2000, p.80), a implantação e a consolidação de um processo permanente de planejamento, o qual "[...] exige ruptura, mas, 
também, continuidade, seqüência, interligação do antes, do durante e do depois, sucessão de estados ou mudanças".

Destarte, a presente avaliação verificou ainda, através do Gráfico 4, que os docentesconcordam que os pressupostos técnico-metodológicos, bem como princípios e técnicas reúnem um conjunto de crenças que tem origem no coletivo entre todos os segmentos da IES.

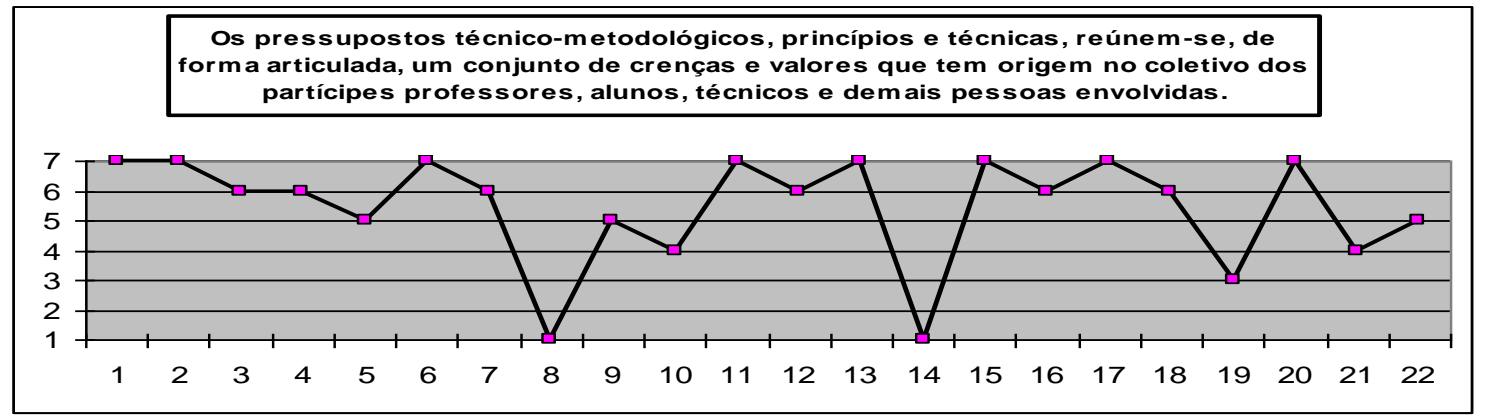

Gráfico 4: PPP: pressupostos técnico-metodológicos

Fonte: Dados da pesquisa, 2009.

A compreensão de considerar a dimensão ética-valorativa dentro da estrutura de um projeto político-pedagógico significa, para Aguilar (1997), resistir às tendências pósmodernas de culto à imagem em detrimento ao conteúdo e a conceber o indivíduo como categoria ética, pensando sua formação pessoal a partir de parâmetros sociais, políticos, técnicos e científicos, visando não ao atendimento da lógica do mercado de trabalho, mas sim a sua transformação.

Já no que diz respeito ao PPP e seu processo de interdisciplinaridade, o Gráfico 5 possibilita uma análise a seu respeito, pois ao ver dos educadores a afirmação prossegue uma vez que o PPP envolve a integração e o engajamento de professores num trabalho conjunto e de integração entre as disciplinas.

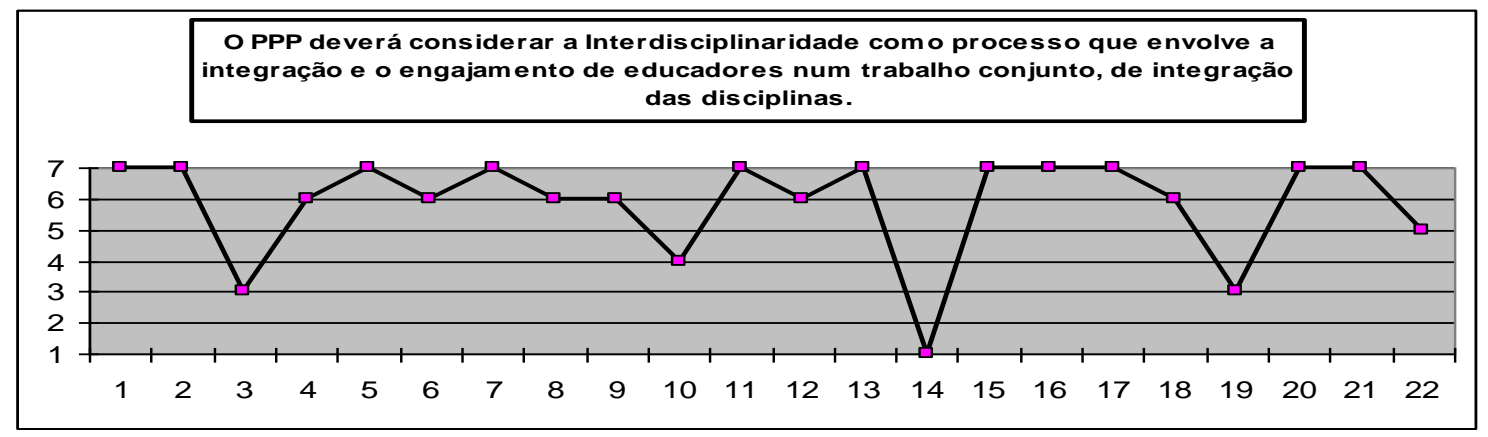

Gráfico 5: PPP: Interdisciplinaridade

Fonte: Dados da pesquisa, 2009.

Ao se buscar respaldo na literatura, compreende-se que com a interdisciplinaridade melhora a formação geral com base num conhecimento mais integrado, articulado e atualizado numa construção auto-suficiente do sujeito, ela permite a abertura de novos campos dos conhecimentos e de novas descobertas que possibilitam uma melhor formação profissional, que favorece até mesmo a educação permanente, da qual se adquire numa metodologia emancipatória traduzida por competência e habilidades que levem o aluno aprender e aprender toda sua existência.(LAFFIN, 2005).

\subsection{Nível de Percepção do Professor no Espaço da IES}

R. Cont. Ufba, Salvador-Ba, v. 4, n. 3, p. 4-19, setembro-dezembro 2010 
Além de procurar analisar os precedentes do PPP na concepção dos docentes, o Bloco 3 do questionário da presente pesquisa ficou encarregado em seu âmago de investigar o nível de percepção do professor de Ciências Contábeis dentro da IES onde desempenha suas atividades enquanto professor

Não obstante, o Gráfico 6 mostra que a quantidade de pontos assinalados acima do ponto 4 da escala de Likert, determinado como nível de percepção desejado segundo a revisão da literatura, foram selecionados de forma significativa, compreendendo assim que para os educadores, o PPP do curso de Ciências Contábeis UFBA promove em sua essência a participação dos sujeitos envolvidos com o processo educativo ${ }^{4}$.

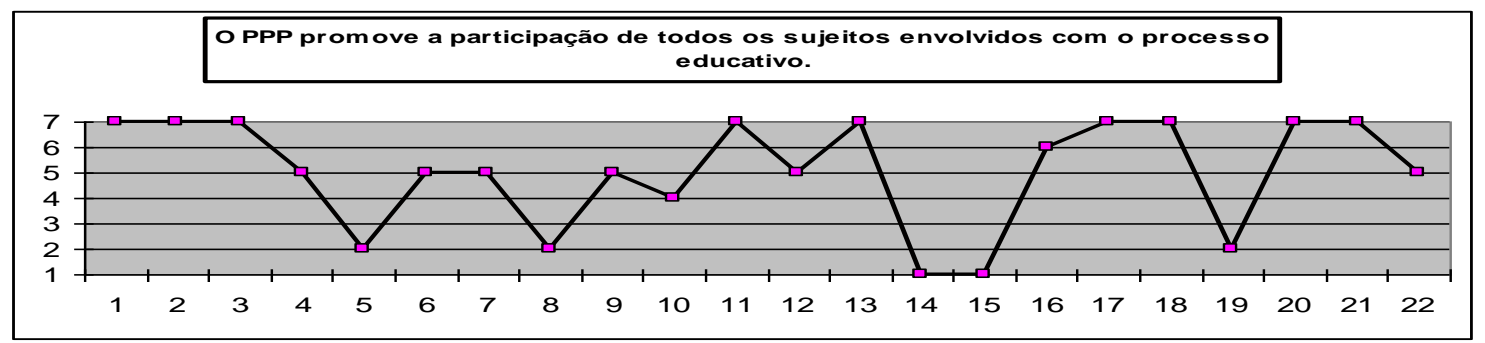

Gráfico 6: PPP: participação de todos os sujeitos envolvidos com o processo educativo

Fonte: Dados da pesquisa, 2009.

Sá (2001, p.71) assevera ainda que mais do que "[...] saber em que momento ocorre a participação (antes, durante ou depois do processo de tomada de decisão); importa também saber qual a proporcionalidade da representação e a substância da própria participação". Disso apreende-se que a representação de um determinado corpo social pode ser majoritária, sem que daí se possa depreender que esse corpo social tem grande influência na instituição educativa, como, quando a participação dos pais é episódica e com função "decorativa", representada apenas em festas, cerimônias e eventos específicos.

O Gráfico 7 também evidencia que a quantidade de respostas assinaladas acima do ponto 4 da escala é superior. Com efeito, isso representa que os professores da FCC/UFBA conhecem o perfil dos alunos que desejam formar. É valido afirmar, contudo, que todas as informações acerca do perfil do aluno e sua pretensões devem ser expressas significativamente no PPP, uma vez que o mesmo deverá reunir informações significativas sobre as intencionalidades e em prol de uma educação de qualidade

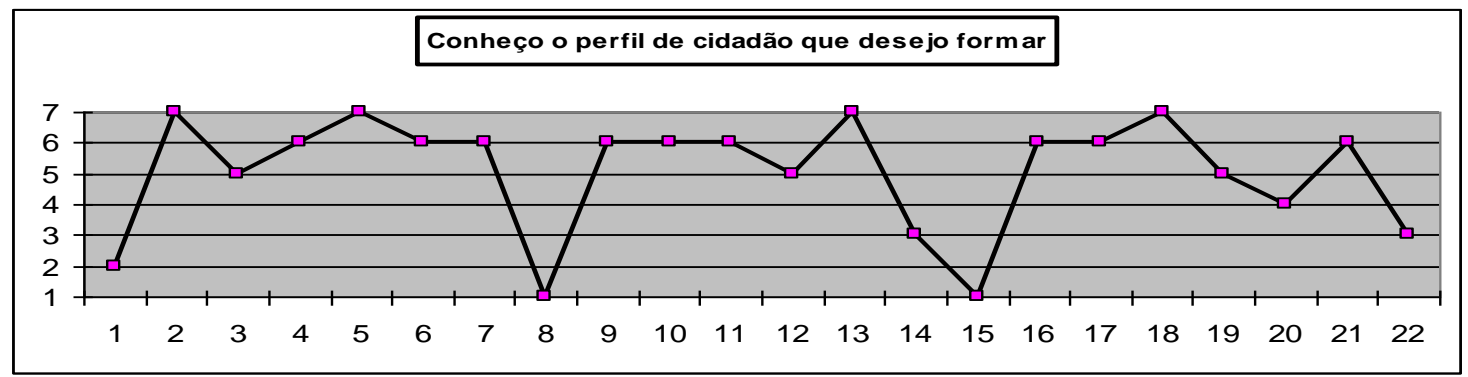

Gráfico 7 - PPP: perfil do aluno

\footnotetext{
${ }^{4}$ A nova LDB (Lei 9394/96) defende a idéia da colaboração, do trabalho em equipe e da construção de um PPP elaborado de forma participativa e colaborativa, originado no seio da coletividade docente, discente e administrativa, dando identidade à IES ou ao curso. É a configuração da singularidade e da particularidade da instituição educativa (VEIGA, 2006).
} 
Para Aguilar (1997, p.8) esse documento deve abranger reflexões em torno das seguintes dimensões: estrutural e conjuntural da sociedade; ética-valorativa; historicidade da instituição e; processo de conhecimento. A primeira dimensão considerada por Aguilar (1997), a dimensão estrutural e conjuntural da sociedade, remete a reflexões acerca da realidade social local e nacional em que a instituição está imersa, ou seja, reporta a questionamentos acerca dos determinantes que condicionam a sua organização no âmbito econômico, político e social. Para contemplar a essa reflexão o autor sugere que se pondere acerca do seguinte questionamento: "[...] que indivíduos estamos formando para viver nesta realidade?".

Embora as dimensões estabelecidas por Aguilar (1997) e os pressupostos delimitados por Veiga (2005) tenham sido concebidos de forma diversa, em essência eles são análogos e complementares. Uma vez que, para a instituição reflexionar sobre os conhecimentos que deseja socializar e produzir, torna-se necessário que ela pondere sobre qual perfil de cidadão deseja formar. Do mesmo modo, para a instituição refletir sobre a sistematização do processo de ensino-aprendizagem é preciso que ela reflita sobre os conhecimentos que em coletivo ela deseja construir e/ou transformar.

Além disso, como pode ser visto no Gráfico 8, a presente pesquisa procurou identificar se o PPP da UFBA, na percepção dos professores, estava condizente com as necessidades da comunidade social e acadêmica local, mediante as ações do currículo e suas atividades extracurriculares. Constata-se uma dispersão muito grande quanto às respostas dos professores, verificando certa insegurança por parte de alguns, acerca deste aspecto tão importante e fundamental que constitui o PPP, o currículo - instrumento de sua concretização.

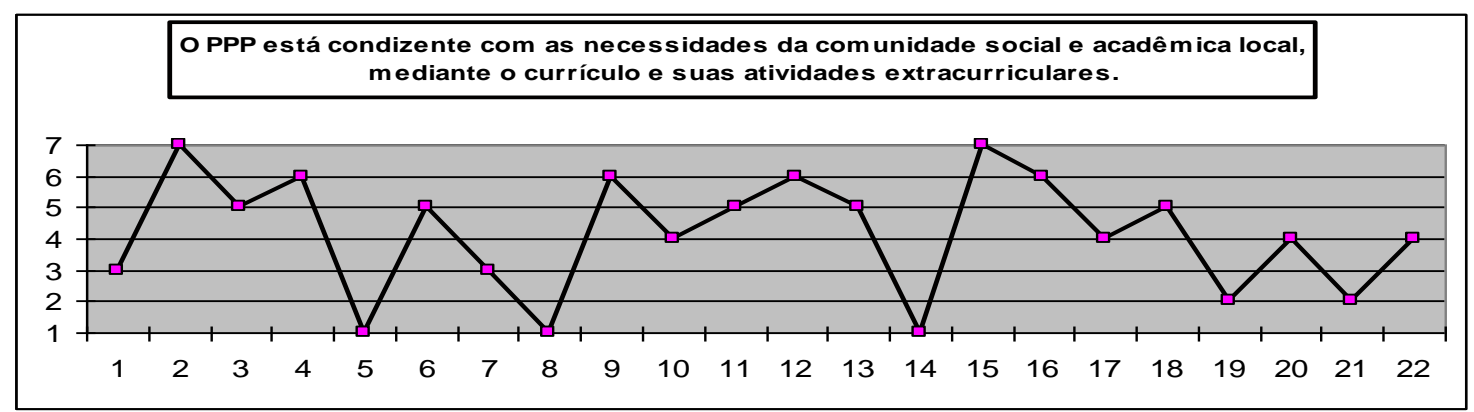

Gráfico 8: PPP: Currículo

Fonte: Dados da pesquisa, 2009.

O currículo deverá ser entendido como um artefato que ao mesmo tempo traz, para instituição, elementos que existem no mundo e cria, na própria instituição sentidos para o mundo - passa a ser visto como ocupando uma posição central nos processos de identidade social, de representação, de regulação moral. O currículo é assim resultante de discursividades diferentes, de intencionalidades diversas, de representações várias, nem sempre mostra, na superfície, tudo que pode mostrar ou significar, em termos de consequiências que pode produzir.

A partir de análises do Gráfico 9, infere-se que em virtude da distribuição proporcional de respostas sobre a escala de Likert, tanto encima quanto abaixo de 4, os professores se dividiram em relação ao conceito exposto. Desta forma, não se garante consistência sobre a elaboração, muito menos na elaboração dos planos de ensino, que são a base de uma educação que possuem um guia, um horizonte a percorrer, que prima no mínimo por ideais e formação humana. 


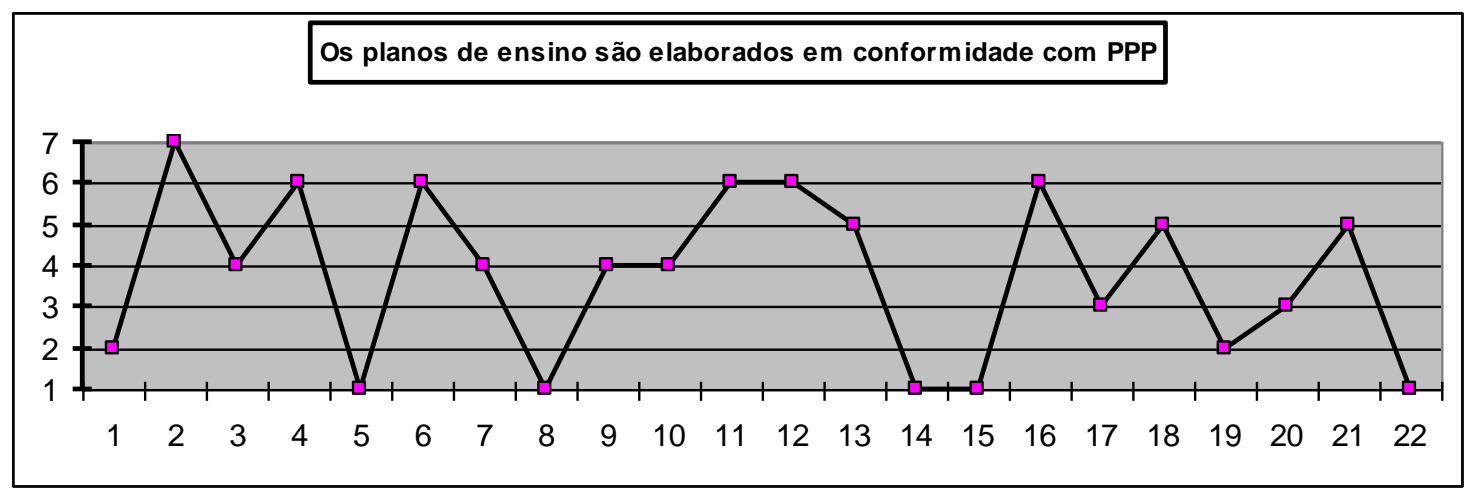

Gráfico 9: PPP: os planos de ensino

Fonte: Dados da pesquisa, 2009.

Disso resulta que o projeto político-pedagógico não se resume a um documento de dimensão pedagógica, "[...] nem muito menos ao conjunto de projetos e de planos isolados de cada professor em sua sala de aula [...]" (Veiga, 2005, p.11), mas sim, um produto específico que reflete a realidade da instituição, "[...] situada em um contexto mais amplo que a influencia e que é por ela influenciado. Em suma, é um instrumento clarificador da ação educativa da instituição em sua totalidade" (VEIGA, 2005, p.12).

Por fim, um outro questionamento pertinente que a pesquisa revelou, dados do Gráfico 10, foi com relação a matriz curricular, que na opinião dos profissionais nem sempre foi fruto de uma discussão coletiva dentro da instituição.

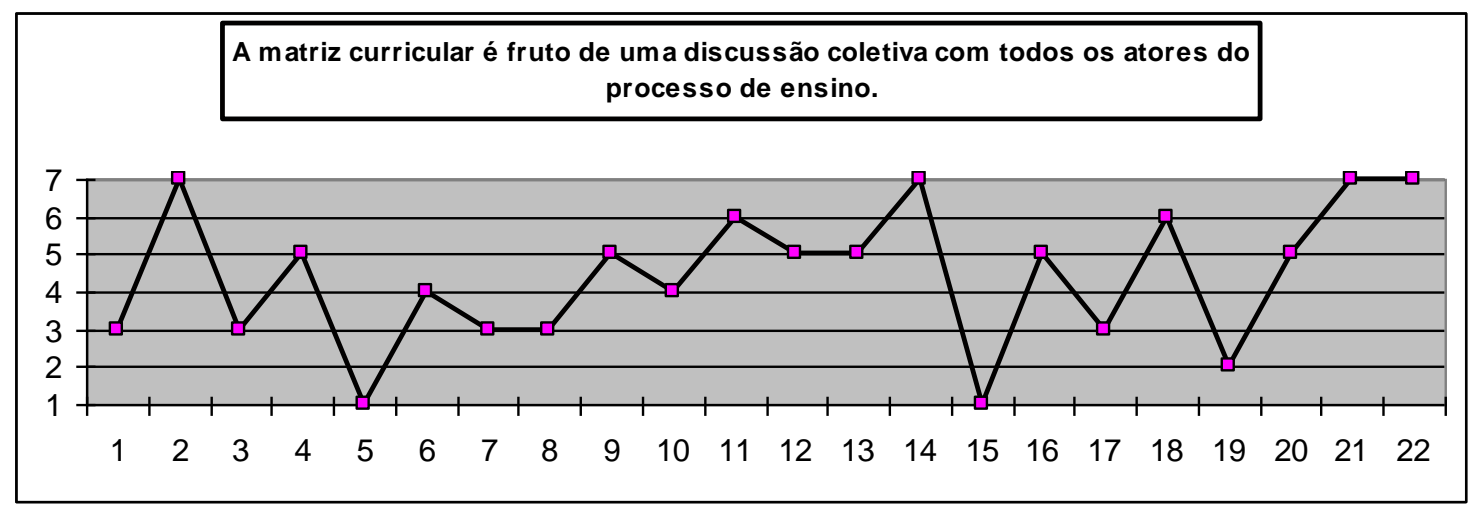

Gráfico 10: PPP: matriz curricular

Fonte: Dados da pesquisa, 2009.

Em vista disto, Marion (1996) e Nossa (1999) lembram que no Brasil são crescentes as necessidades de reformulações no ensino Contábil, por isso podem causar problemas uma vez que não atraia alunos com qualidade, a perda da relevância do currículo e o não desenvolvimento de habilidades de atributos por parte do curso. Com isso, percebe-se que pouco é feito para redução de disparidades entre o que se propõe na matriz curricular e o que se é feito na prática. Assim, é de conhecimento geral, que os profissionais de contabilidade serão muitos afetados pela evolução da tecnologia de informação e, portanto, é necessário que o ensino contábil acompanhe a evolução através da reestruturação de aprendizagem.

\section{CONSIDERAÇÕES FINAIS}

$\mathrm{Na}$ busca de transformação, as Instituições de Ensino Superior (IES) planejam e realizam ações que viabilizam o processo de qualificação do ensino público. Contudo, as alterações em decorrência das mudanças curriculares têm sido hoje uma prática comum nas 
universidades, pois as discussões sobre o PPP dos cursos perpassam pelas disciplinas básicas e profissionalizantes, se possuem ou não atividades interdisciplinares, se as aulas práticas atendem ou não às necessidades dos alunos, se os programas estão ou não atualizados com o mercado, se os cursos estão preocupados ou não com as tecnologias e a partir daí pensam em organizar uma nova abordagem curricular.

Desta forma, o presente estudo procurou investigar o nível de percepção dos professores de Ciências Contábeis da Universidade Federal da Bahia (UFBA), acerca do Projeto Político-Pedagógico. A fim de contemplar o objeto e os objetivos propostos, o tipo de pesquisa desenvolvida neste trabalho foi sob a forma do estudo de caso, de caráter descritivo. Para tanto, utilizou-se o questionário enquanto técnica de coleta de dados em escala do tipo Likert de 1 a 7, composto de três blocos: no primeiro procurou-se verificar o perfil do professor de Ciências Contábeis da UFBA; no segundo analisar os precedentes do projeto político-pedagógico e, posteriormente, constatar o nível de percepção do professor de Ciências Contábeis dentro da IES onde desempenha suas atividades de docência.

Com relação ao perfil do professor de ciências contábeis da UFBA, a pesquisa concluiu que exite pouca atuação de mulheres em sala de aula, pois o gênero masculino predominou tanto em formação acadêmica, quanto na atuação em coordenação pedagógica de curso e tempo de docência no ensino superior. Já com relação aos precedentes do PPP, verificou-se que na percepção dos educadores o mesmo é um instrumento que possibilita reflexão do processo educativo, consistente e factível, refletido no geral um nível de percepção satisfatório frente à literatura.

Não obstante, a pesquisa evidenciou que é importante perceber que a construção do PPP requer continuidade das ações, descentralização, democratização do processo de tomada de decisões e instalações de um processo coletivo de avaliação de cunho emancipatório. Em meio as suas experiências, os professores afirmaram que conhecem o perfil dos alunos que desejam formar e que o PPP do curso de Ciências Contábeis UFBA promove em sua essência a participação dos sujeitos envolvidos na comunidade acadêmica.

Faz-se necessário destacar que as considerações realizadas no presente trabalho não se constituem enquanto conclusões definitivas nem se esgotam por si mesmas, fazendo-se, portanto, necessários novos estudos acerca desta temática. Para que haja aplicabilidade e efetividade dos conceitos que permeiam o Projeto Político Pedagógico deverá ser entendido como um instrumento que tem a função de ser orientador e condutor do presente e do futuro. Neste sentido, sua intenção é a de projetar, lançar, orientar, dar direção às idéias e aos processos pedagógicos alicerçados nas reflexões e ações do corpo docente.

Por fim, entende-se que um nível de percepção coerente e/ou desejável sobre o PPP, é condição para que se afirme (ou se construa simultaneamente) a identidade da IES, como um espaço pedagógico necessário à construção do conhecimento e da cidadania. Pois, como instrumento de planejamento educacional, é no PPP onde são definidas as prioridades e necessidades de uma instituição universitária, para o direcionamento de sua atuação rumo à qualidade de ensino superior, sem olvidar que atrás de um PPP ficam resgatadas a identidade da instituição, sua intencionalidade e a revelação de seus compromissos.

\section{REFERÊNCIAS}

AGUILAR, L. E.. La gestión de la educación: su significado a partir de propuestas pedagógicas institucionales. Ministerio de Educación y Cultura, Universidad Nacional de La Rioja, mímeo, La Rioja, Argentina, 1997.

BERNSTEIN, Brasil. Classes, códigos y control. Madri: Akal, 1989. 
BRASIL. Ministério da Educação. Secretaria de Educação Superior. Diretrizes curriculares para os cursos de graduação. Disponível em: <http://www.mec.gov.br〉. Acesso em: 18 outubro de 2009.

BUSSMANN, A. C.. O projeto político-pedagógico e a gestão da escola. In: VEIGA, I. P. A. (org.). Projeto político-pedagógico da escola: uma construção possível. Campinas, SP: Papirus, 1996.

DEMO, Pedro. A nova LDB - Ranços e Avanços. Campinas: Papirus, 1997.

DEWEY, J. Democracy and education. New York: McMillan,1916.

FREIRE, Paulo. Educação e mudanças: saberes necessários à prática educativa. 30 ed., São Paulo: Paz e Terra, 2007.

GUIMARÃES, Isac. P. ; GOMES, Sônia Maria da S. ; SLOMSKI, Vilma G. ; SILVA, Antonio Carlos Ribeiro ; OLIVEIRA, Marcelo R. . Uma análise dos projetos políticopedagógicos dos cursos de Ciências Contábeis das universidades públicas da Bahia.. Revista Brasileira de Contabilidade, v. 178, p. 10-15, 2009.

GUIMARÃES, Isac. P. ; SLOMSKI, Vilma G. ; ARAÚJO, Adriana M. Procópio; SILVA, Antonio Carlos Ribeiro ; GOMES, Sônia Maria da S. . Saberes que fundamentam a prática pedagógica do professor de Ciências Contábeis de instituições de ensino superior brasileiras. Revista Brasileira de Contabilidade, v. 178, p. 25-40, 2009.

IUDÍCIBUS, Sérgio de. MARION, José Carlos. As Faculdades de Ciências Contábeis e a Formação do Contador. Revista Brasileira de Contabilidade, Brasília, 1985.

KWIEK, M. The Internationalization and Globalization in Central and East European Higher Education. Society for Research in Higher Education International News, $N^{\circ} 47$, November: p. 3-5, 2001.

LAFFIN, Marcos. De contador a Professor: A trajetória da docência no ensino superior de Contabilidade. Florianópolis, SC: UFSC, 2005.

LÜDKE, Menga; ANDRÉ, Marli. Pesquisa em educação: abordagens qualitativas. São Paulo: EPU, 1986.

MARION, J. C. O ensino da contabilidade. São Paulo: Atlas, 1996.

McCLELLAND, D. C. Testing for competence rather than for intelligence. American Psychologist: January,. 1973, p. 1-14.

MINISTÉRIO DA EDUCAÇÃO, Conselho Nacional de Educação. Resolução CNE/CES 10/2004, de 16 de dezembro de 2004. Disponível em: http:// www.mec.gov.br/cne. Acesso em: 28 jun. 2008.

NOSSA, Valcemiro. Formação do corpo docente dos cursos de graduação em Contabilidade no Brasil: Uma análise crítica. Cadernos de Estudos FIPECAFI. São Paulo: FEA/USP , v. 11, n. 21, p. 74-92, mai./ago. 1999.

R. Cont. Ufba, Salvador-Ba, v. 4, n. 3, p. 4-19, setembro-dezembro 2010 
OLIVEIRA, D. A.. Educação e planejamento: a escola como núcleo da gestão. In: Gestão democrática da Educação: desafios contemporâneos. Petrópolis: Vozes, 1997.

ROSSA, L.. Armadilhas do projeto político-pedagógico. Revista de Educação AEC. Brasília, DF, n. 117, out./dez. de 2000.

SÁ, V.. A (não) participação dos pais na escola: a eloqüência das ausências. In: VEIGA, I.P. A.; FONSECA, M. (org.). As dimensões do projeto políticopedagógico. Campinas, SP: Papirus, 2001.

SILVA, Antonio Carlos $\mathrm{R}$ da. Metodologia da Pesquisa Aplicada à Contabilidade: orientações de estudos, projetos, artigos, relatórios, monografias, dissertações, teses. 2. ed. São Paulo: Atlas, 2006.

VASCONCELlOS, C. S. Planejamento: Plano de Ensino-Aprendizagem e Projeto Educativo. São Paulo: Libertat, 2006.

VEIGA, Ilma Passos A. (Org.) Projeto Político-Pedagógico: uma construção possível. 17. ed. Campinas: Papirus, 2004.

Escola: Espaço do Projeto Político-Pedagógico. 8. ed. Campinas: Papirus, 2005.

Lições de Didática. São Paulo: Papirus, 2006.

WALLACE, M. Managing the Unmanageable?: Coping with Complex Educational Change. Educational Management \& Administration, Vol 31, p. 9-29, 2003.

YIN, Robert K. Estudo de caso : planejamento e métodos. 2. ed. Porto Alegre: Bookman, 2001.

ZAULI, E. M. Crise e reforma do Estado: condicionantes e perspectivas da descentralização de políticas públicas. In: OLIVEIRA, D. A.; DUARTE, M. R. T. (org.). Política e trabalho na escola: administração dos sistemas públicos de educação básica. 3.ed. Belo Horizonte: Autêntica, 2003. 